\title{
Finansal ve Finansal Olmayan Verilerle Menü Performansının Değerlendirilmesi
}

Evaluation of the Menu Performance with Financial and Non-Financial Data

\author{
Vedat YiĞiToĞLU**, G. Nilüfer TETiK*** \\ **(Sorumlu Yazar) Dr. Öğr. Üyesi, Akdeniz Üniversitesi, Manavgat Turizm Fakültesi, Gastronomi ve Mutfak Sanatları Bölümü, 07600, Manavgat-Antalya. \\ E-posta: viyitoglu@akdeniz.edu.tr \\ ORCID: 0000-0003-2215-1961 \\ ***Prof. Dr., Emekli Öğretim Üyesi, 07000, Antalya. \\ E-posta: niltetik@akdeniz.edu.tr \\ ORCID: 0000-0001-6434-8039
}

MAKALE BILGILERI

Makale işlem bilgileri:

Gönderilme tarihi: 17 Nisan 2019

Düzeltme: 5 Temmuz 2019

Kabul: 9 Temmuz 2019

Anahtar sözcükler: Menü analizi,

Veri zarflama analizi, Yiyecek perfor-

mansi, Yiyecek tüketimi, Restoranlar.

\section{ARTICLE INFO}

Article history:

Submitted: 17 April 2019

Resubmitted: 5 July 2019

Accepted: 9 July 2019

Key words: Menu analysis, Data envelopment analysis, Food performance, Food consumption, Restaurants.

\begin{abstract}
ÖZ
Bu çalışmada yiyecek menü kalemlerinin performansının finansal ve finansal olmayan verilerle etkin bir şekilde ortaya koyulması amaçlanmıştır. Bu amaçla Antalya'da bulunan lüks bir restoran işletmesinin 30 adet yiyecek kaleminden olusan akșam yemeği menüsü örnekleminde bir arastırma yapılmıștır. Bir aylık faaliyet dönemini kapsayan araştırma verileri; yüz yüze görüşme, belge inceleme ve görsel kayıt teknikleri kullanılarak toplanmış ve girdi odaklı Veri Zarflama Analizi ile analiz edilmiştir. Yapılan analiz sonucunda, menü kalemlerinin büyük bir kısmının (16'sının) etkin olduğu belirlenmiștir. Ancak etkin olan menü kalemlerine menü grupları bazında bakıldığında, en az sayıda ana yemek grubunda yer alan yiyeceklerin (ikisinin) etkin olduğu anlaşıımıştır. Bu sonuç, işletme yönetiminin özellikle ve öncelikle ana yemek grubunda yer alan yiyecekler üzerinde odaklanması gerektiğini göstermektedir. Çalıșmada mevcut yazından farklı olarak ilk defa yiyecek tüketimi önemli bir çıktı değişkeni olarak kullanılmıştır. Böylece menü değerleme sürecine işletmeyle birlikte konuk bakış açısı da dâhil edilmiş ve daha kapsamlı sonuçlar elde edilmiştir.
\end{abstract}

\begin{abstract}
The purpose of the study is to explore the performance of the menu items effectively through financial and non-financial data. In the research, a case study was conducted in a fine-dining restaurant in Antalya and 30 menu items in dinner menu were taken into consideration. The data was collected using face-to-face interview, document review and visual recording techniques and analyzed with input-oriented Data Envelopment Analysis. As a result of the analysis, it was determined that most of the menu items (16 items) were effective. However, when the distribution of menu groups is examined, it has been concluded that the number of the items which were effective was the least (two items) in the main course. This result shows that management should focus on food in the main category particularly and primarily. In the study, food consumption was used as an important output variable for the first time. Thus, guest perspective was included in the menu evaluation process with the business perspective and more comprehensive results were obtained.
\end{abstract}

\section{Giriş}

Menüler, restoran işletmelerinin faaliyet merkezinde yer almakta (Kivela 2003); satın alma, depolama, üretim, servis, pazarlama ve denetim

*Bu çalışma, Akdeniz Üniversitesi Sosyal Bilimler Enstitüsü Turizm İşletmeciliği ve Otelcilik Ana Bilim Dalında, Prof. Dr. G. Nilüfer TETIK danışmanlığında yazılan, "Menü Analizinde Zaman Etkenli Faaliyet Tabanlı Maliyetleme ve Veri Zarflama Analizinin Birlikte Kullanılması: Lüks Bir Restoran İşletmesinde Uygulama" başlıklı doktora tezinden üretilmiştir. gibi hemen hemen bütün işletme kararlarını anlamlı şekilde etkilemektedir (Atikson ve Jones 1993; Kotschevar ve Withrow 2008). Dolayısıla menüde yer alacak her bir yiyecek kaleminin hassas, kapsamlı ve en doğru şekilde değerlendirilmesi gerekir. Bu amaçla 1980'li yıllardan itibaren çok sayıda menü analiz yaklaşımı geliştirilmiştir (Miller 1980; LeBruto vd. 1995; Raab ve Mayer 2007). Menü analizi (MA) konusunda yapılmış araştırmalar incelendiğinde menü kalem- 
lerinin performanslarının değerlendirilmesinde çoğunlukla maliyet, satış miktarı, katkı payı, fiyat gibi sınırlı sayıda finansal verinin kullanıldığ anlaşılmaktadır (Taylor vd. 2009; Özdemir 2012). Bu bağlamda elde edilen analiz sonuçları, kapsam ve güvenirlilik bakımından eleştiriye açıktır. Çünkü menü kalemlerinin servis süresi (Gupta vd. 2007), hazırlık zorluğu (Taylor vd. 2009), besin değerleri (Fakih vd. 2016), menü kartındaki konumu (Kwong 2005) gibi finansal olmayan bir takım etmenler de doğrudan ve dolaylı olarak menü performansı üzerinde etkili olabilmektedir. Dolayısıyla daha etkin menü değerlendirmeleri için menü performansı üzerinde etkili olabilen mümkün olabildiğince fazla sayıda ve farklı nitelikte etmenin analiz sürecine dâhil edilmesi gerekir. Bu noktada ön plana çıan uygulamaların başında Veri Zarflama Analizi (VZA) gelmektedir (Wöber 2007; Emrouznejad vd. 2008; Liu vd. 2013).

VZA, birimlerin performansı üzerinde etkili olan çok sayıda faktörü birlikte dikkate alarak etkinlik belirleyen bir tekniktir (Taylor vd. 2009). $\mathrm{Bu}$ teknik yardımıyla girdi ve çıktı değişkenleri adı altında istenen sayı ve nitelikte veri kullanılarak birimlerin performansı çok daha kapsamlı ve esnek bir şekilde ortaya koyulabilmektedir (Haksever ve Render 2013). Dolayısıyla VZA, farklı özelliklere sahip sektörlerin, işletmelerin ya da birimlerin performans ölçümümünde kullanılabilen esnek bir teknik olarak esnek bir teknik olarak uluslararası ölçekte çok sayıda çalışmaya konu olmuştur (Emrouznejad vd. 2008; Liu vd. 2013).

Turizm yazınında yer alan VZA çalışmaları incelendiğinde, yiyecek hizmet işletmeleri örnekleminde yapılmış çalışma sayısının sınırlı olduğu görülmektedir (Wöber 2007). Diğer taraftan sinırlı sayıdaki bu çalışmalarda menü kalemleri değil, genellikle farklı restoran işletmelerinin performansları karşılaştırmalı olarak ortaya konmuştur (Banker ve Morey 1986; Reynolds ve Thomson 2007; Taylor vd. 2009). Dahası ulusal yazında, gerek restoran örnekleminde gerekse menü kalemleri örnekleminde yapılmış tek bir VZA çalışmasına dahi ulaşılamamıştır. Bu açıdan bakıldığında, yazına katkı sağlaması açısından, VZA ile yapılan menü değerlendirme çalışmalarına gereksinim olduğu açıtır.

VZA gücünü, analiz sürecine dâhil edilen girdi ve çıktı değişkenlerinden alan bir tekniktir (Haksever ve Render 2013). Girdi ve çıktı değişkenlerinin ya da bu değişkenlerin değerlerinin değişmesiyle farklı performans sonuçlarının ortaya çıkması beklenir. Eksik ya da yanlış değişkenlerin kullanılması durumunda ise olumsuz etkileri çok derin olabilecek yanıltıcı sonuçların elde edilmesi söz konusudur (Wagner ve Shimshak 2007). Diğer taraftan her işletmenin kendine has bir takım özellikleri bulunmaktadır. Bu nedenle bir işletme için çok önemli olan bir etmen, başka bir işletme için daha az önemli ya da tamamen önemsiz olabilir. Dolayısıyla bir işletmede etkin sonuçlar veren bir VZA uygulaması, başka bir işletmede hatalı sonuçlar ortaya çıkarabilmektedir. Bu nedenle VZA ile yapılan menü uygulamala$\mathrm{r}$, farklı işletme örnekleminde ve her işletme için farklı performans etmenleri kullanılarak ayrı ayrı olarak yapılmalıdır.

\section{ALANYAZIN TARAMASI}

\section{Menü Analizi}

Menü ile ilgili yazın incelendiğinde, ilgili çalışmaların büyük bir kısmının menü analizi (MA) üzerinde odaklandığı görülmektedir (Özdemir ve Çalışkan 2014). MA genel ifadeyle menü kalemlerinin performanslarının sistematik olarak belirlenmesi ve değerlendirilmesidir (Atkinson ve Jones 1993). Akademik anlamda ilk MA yaklaşımı, matris tabanlı olarak Miller (1980) tarafından oluşturulmuş ve böylece bilimsel MA çalışmalarının yolu açılmıştır. Sonraki yıllarda ilgili çalışmalar hızla artmaya başlamış ve menü performansının daha doğru belirlenmesi adına fark1 analiz yaklaşımları geliştirilmiştir (Kasavana ve Smith 1982; Pavesic 1983; Bayou ve Bennett 1992). Ancak geliştirilmiş MA yaklaşımlarının büyük bir kısmı, sınırlı sayıda değişken içermesi ve buna bağlı olarak kısıtlı sonuçlar sağlaması bakımından eleştirilmektedir (Taylor vd. 2009; Özdemir 2012). Diğer taraftan yazında sıklıkla kullanılan maliyet, satış miktarı, katkı payı ve fiyat gibi sınırlı değişkenler temelde finansal özel- 
lik göstermektedir. Bu bağlamda ilgili analiz yaklaşımları daha çok işletme bakış açısını yansıtmakta ve genellikle kısa vadeli amaçlara hizmet etmektedir. Bu nedenle son yıllarda MA sürecinde farklı nitelikte ve daha fazla sayıda değişkeni birlikte değerlendiren çok boyutlu analiz yaklaşımları geliştirilmeye başlanmıştır.

İlk defa Taylor vd. (2009) menü analiz kapsamında VZA'yı kullanarak farklı nitelikte çok daha fazla sayıda değişkeni analize dâhil etmiş (hazırlık zorluğu, satıcı sayısı, işlem sayısı, brüt kâr ve satış hacmi) ve böylece daha kapsamlı analiz sonuçları ortaya koymuştur. Bununla birlikte bazı yazarlar, VZA ile yapılan etkin bir menü analizinin işletme kârlılığını önemli düzeylerde arttırabildiğini ileri sürmektedir (Fang ve Hsu 2012; Fang vd. 2013). VZA ile yapılan menü analizi sayesinde restoran yöneticileri, etkin olmayan menü kalemleriyle ilgili daha somut ve daha önemli bilgiler elde edebilmektedir. Bu bağlamda yöneticiler, etkin olmayan her bir menü kaleminin etkin olabilmesi için hangi girdi ve çıktı değişkenlerini, nasıl ve ne düzeyde değiştirmeleri gerektiğini net bir şekilde görebilmektedir.

\section{Veri Zarflama Analizi}

VZA, çok sayıda girdi ve çıktısı olan işletmeler ya da faaliyetler için kullanılabilen parametrik olmayan bir etkinlik ölçüm tekniğidir (Liu vd. 2013: 3). Bu teknik ilk olarak 1978 yılında Charnes, Cooper ve Rhodes (CCR) tarafından yapılan bir çalışma ile ortaya çıkmış ve hızlı bir şekilde gelişerek küresel ölçekte en popüler performans ölçüm yöntemlerinden biri haline gelmiştir. Bu bağlamda gerek teorik gerekse uygulama açısından binlerce bilimsel çalışmaya ve uygulamaya konu olmuştur (Emrouznejad vd. 2008; Liu vd. 2013).

Turizm yazınında yer alan VZA çalışmaları incelendiğinde daha çok turizm bölgeleri ve konaklama işletmeleri üzerinde odaklanıldığı görülmektedir (Wöber 2007). Yiyecek hizmet işletmeleri örnekleminde yapılmış çalışma sayısı ise nispeten daha az olmakla birlikte bu çalışmalarda genellikle menülerin değil, farklı restoran işletmelerinin performansı ortaya koyulmuştur (Banker ve Morey 1986; Reynolds ve Thomson
2007). Bu açıdan değerlendirildiğinde yiyecek menü performansının VZA ile ortaya koyulduğu çalışmalara gereksinim olduğu düşünülmektedir.

VZA uygulaması genel olarak dört ana aşamadan oluşmaktadır. Bunlar; performansı ortaya koyulacak karar birimlerinin belirlenmesi (1), kullanılacak girdi ve çıktı değişkenlerinin belirlenmesi (2), VZA modelinin belirlenmesi (3) ve analiz sonuçlarının yorumlanmasıdır (4). Başarılı VZA uygulamaları için ilgili aşamaların hassas ve sıralı olarak dikkate alınması önemlidir. Bu çalışmada performansı ortaya koyulacak karar birimleri (KB) örnek restoran işletmesinin akşam yemeği menüsünde yer alan 30 adet yiyecek kalemidir. KB belirlendikten sonra ikinci aşamada girdi ve çıktı değişkenlerinin belirlenmesi gerekir. VZA uygulama sürecinde girdi ve çıtı faktörlerinin belirlenmesi analiz sürecinde muhtemelen en zorlu ve en hassas hususlarm başında gelmektedir. Uygun girdi ve çıktı değişkenlerinin belirlenmesinde verilerin elde edilebilirliği dikkate alınmış ve alanyazın incelemesi yapılmıştır. Yapılan incelemede menü performans değerlendirmelerinde kullanılan başlıca girdi ve çıktı değiş̧kenleri Tablo 1'de özetlenmiştir. Tabloda görüldüğü üzere geçmiş yıllarda yapılmış benzer çalışmalarda en popüler girdi değişkeni olarak malzeme maliyeti ve işgücü maliyetinin, en popüler çıktı değişkeni olarak ise satış miktarı ve brüt kar verilerinin kullanıldığı anlaşılmaktadır. Bu nedenle ilgili değişkenlerin aynı şekilde yapılan çalışmada da kullanılmasına karar verilmiştir.

Diğer taraftan restoran hizmetleri açısından zaman faktörü çok önemli bir kaynaktır (Chou ve Fang 2013). Dolayısıyla menü faaliyet (hazırlı/ servis) süresi ve hazırlık zorluğu da ayrı girdi değişkeni olarak analiz sürecine dâhil edilmiştir. Son olarak konuk bakış açısını yansıtması bakımindan yiyecek tüketim düzeyinin de ilk defa ayrı bir çıktı değişkeni olarak kullanılmasına karar verilmiştir. Çünkü yiyecek tüketimi, gerçekte bir yiyeceğin konuklar tarafından ne düzeyde beğenildiğini ortaya koyan önemli göstergelerden biri olarak kabul edilmektedir (Ferreira vd. 2013; Massow ve McAdams 2015). Bu bağlamda, Connors ve Rozell (2004) sağlık hizmetleri ala- 
Finansal ve Finansal OImayan Verilerle Menü Performansının Değerlendirilmesi

Tablo 1. VZA-Menü Analizi Yazınında Kullanılmış Başlıca Girdi ve Çıktı Değişkenleri

\begin{tabular}{|c|c|c|c|c|c|c|}
\hline Değişkenler & $\begin{array}{r}\text { Chou ve Fang } \\
\text { (2013) }\end{array}$ & $\begin{array}{l}\text { Fang vd. } \\
\text { (2012) }\end{array}$ & $\begin{array}{r}\text { Fang ve Hsu } \\
\text { (2013) }\end{array}$ & $\begin{array}{l}\text { Peng vd. } \\
(2011)\end{array}$ & $\begin{array}{l}\text { Reynolds } \\
\text { ve Taylor } \\
\text { (2011) }\end{array}$ & $\begin{array}{r}\text { Taylor vd. } \\
\text { (2009) }\end{array}$ \\
\hline Malzeme Maliyeti & Girdi & Girdi & Girdi & Girdi & - & Girdi \\
\hline İşgücü Maliyeti & Girdi & Girdi & Girdi & Girdi & - & - \\
\hline Diğer Faaliyet Giderleri & - & Girdi & - & - & - & - \\
\hline Satıcı Sayısı & Girdi & - & Girdi & - & Girdi & Girdi \\
\hline İşlem Sayısı & - & - & - & Girdi & Girdi & Girdi \\
\hline Pişirme Basamakları & Girdi & - & - & - & - & - \\
\hline Birim Fiyat & Girdi & - & - & - & - & - \\
\hline Servis/Hazırlık Süresi & Girdi & - & - & - & - & - \\
\hline Hazırlık Zorluğu & - & - & - & - & Girdi & - \\
\hline Satış hacmi & Çıktı & - & Çıktı & Çıktı & Çıktı & Çıktı \\
\hline Brüt Kâr & - & Çıktı & Çıktı & Çıktı & Çıktı & Çıktı \\
\hline Net Kâr & Çıktı & - & - & - & - & - \\
\hline Gelir & - & Çıktı & - & Çıktı & - & - \\
\hline VZA Modeli & CCR-BCC & $\mathrm{BCC}$ & $\mathrm{BCC}$ & $\mathrm{BCC}$ & $\mathrm{BCC}$ & CCR \\
\hline
\end{tabular}

nında yaptıkları bir çalışmada, tabak artık verilerinin (dolayısıyla tabak tüketiminin) menü değerlendirme sürecinde etkili bir şekilde kullanılabileceğini ileri sürmüştür. Nitekim yakın bir geçmişte beş yıldızlı otel işletmelerinde çalışan mutfak şefleri örnekleminde yapılmış bir araştırmada, tabak artıklarının öznel olarak menü analiz sürecinde dikkate alındı̆̆ı ortaya koyulmuştur (Özdemir ve Nebioğlu 2015).

\section{YÖNTEM}

Araştırma, gönüllülük esası dikkate alınarak Antalya-Kaleiçi bölgesinde yer alan lüks bir restoran işletmesinde yapılmıştır. İlgili restoran işletmesinin akşam yemeği, öğle yemeği ve şarap menüsü olmak üzere üç farklı menüsü bulunmaktadır. Araştırmada sadece akşam yemeği menüsünde yer alan yiyecek kalemleri dikkate alınmıştır. Çünkü akşam yemekleri, lüks restoran konseptinin en temel unsurlarından biridir (Walker 2011). Akşam yemeği menüsünde 11 adet başlangıç, 10 adet ana yemek ve dokuz adet tatlı olmak üzere toplam 30 adet menü kalemi bulunmaktadir. Başlangıç grubunda Avokado Salatalı Jumbo Ka- rides (A1), Ricotta ve Ispanak Ravyoli (A2), Somon Quartet (A3), Tempura Sebzeler (A4), Keçi Peynirli Patlıcan Sufle (A5), Porcini Mantarlı Tagliatelle (A6), Moules Marınıere (A7), Sicilya Usulü Sübye (A8), Dana Carpaccio (A9), Kalamar Halkaları (A10) ve Peynir Selection (A11) yiyecek kalemleri yer almaktadir. Ana yemek grubunda ise Kuzu Cotlet (B1), Ateşte Tavuk (B2), Bonfser (B3), Beef Wellington (B4), Kömür Alevinde Antrkot (B5), Fırınlanmış Bıldırcın Dolması (B6), Ördek Confi (B7), Akdeniz Esintisi (B8), Asma Yaprağında Levrek (B9) ve Oltadan Balık (B10) yiyecek kalemlerinden oluşmaktadır. Tatlı grubunda yer alan yiyecekler ise Dilly's Çikolata Efsanesi (C1), Sultan Kahvesi (C2), Krep Egzotik (C3), Bir Yaz Rüyası (C4), Tarte Tatin (C5), Truffle Donuts (C6), Yağmur Damlaları (C7), Profiterol (C8) ve Pretty Woman (C9) menü kalemleridir. Çalışmada kolaylık olması için yiyeceklerin adları yerine parantez içindeki kodları kullanılmıştır.

Verilerin toplanması sürecinde bir aylık bir faaliyet dönemi dikkate alınmıştır. Bu kapsamda 2013 Eylül ayı içinde farklı günlerde olmak üzere toplam sekiz günde, akşam servisinin yoğun 
olduğu 20-22 saatleri arasında restoran işletmesine ziyaretler yapılmıştır. Yapılan bu ziyaretlerde menü malzeme maliyeti standart reçetelerle, menü satış fiyatları menü kartıyla, menü satış miktarları adisyon kayıtlarıyla, personel ve enerji giderleri işletme yöneticisiyle yapılan yüzyüze görüşmeyle, menü kalemi faaliyet süresi ve zorluk düzeyleri mutfak şefiyle yapılan görüşmelerle, menü yiyecek tüketimi ise görsel kayıtla toplanmiştır.

Çalışmada her bir menü kaleminin tüketim miktarı tabak artık analizi yapılarak belirlenmiştir. Tabak artık analizi yapılırken öncelikle her bir menünün standart görünümü kayıt altına alınmıştır. Daha sonra konuk tüketiminden dönen tabakların kayıtları alınarak bu standart kayıtlarla karşılaştırılmış ve Sherwin vd. (1998) tarafından geliştirilmiş olan yedi derecelendirmeli (hiç kalmamış, bir lokma kalmış, 1/4'ü kalmış, 1/2'si kalmış, 3/4'ü kalmış, bir lokma alınmış ve hepsi kalmış) ölçek ile değerlendirme yapılmıştır. Tabak artık miktarı belirlenirken tereddüt yaşanan kayıtlarda mutfak yetkilisinden destek alınmış, böylece elde edilen sonuçların güvenirliliğinin arttırılması amaçlanmıştır. Diğger taraftan yiyeceklerin zorluk düzeyleri ise en kolay (1) ve en zor (5) arasında değişen beş dereceli Likert bir ölçekle ortaya koyulmuştur (Reynolds ve Taylor 2011).

Elde edilen verilerin analizi VZA ile gerçekleştirilmiştir. VZA uygulamalarında temel olarak ölçeğe göre sabit getiri varsayımı altında (CCR) ve ölçeğe göre değişken getiri varsayımı altında (BCC) olmak üzere iki farklı model kullanılmaktadır. CCR Modeli işletmelerin en uygun düzeyde çalıştıklarını kabul etmektedir. Dolayısıyla KB'lerin en iyi düzeyde faaliyette bulundukları düşünülüyorsa, CCR modeli kullanılmalıdır. Diğer taraftan girdi ve çıktıların kontrol edilme durumuna göre nihai VZA modeli belirlenmelidir. Girdi üzerinde denetim mevcutsa girdiye yönelik, çıtı üzerindeki denetim söz konusu ise çıktıya yönelik modeller tercih edilmelidir. Günümüzün rekabet ve üretim koşulları restoranların en uygun ölçekte faaliyette bulunmasını zorlaştırırken, yöneticilerin çıktılar üzerindeki denetim gücünü de sınırlamaktadır. Bu nedenle çalışmada; Banker, Charnes ve Cooper (1984) tarafından geliştirilmiş ölçeğe göre değişken getiri varsayımlı BCC VZA Modeli girdi odaklı olarak kullanılmıştır. Bu kapsamda ticari olmayan DEAP 2.1 (Data Envelopment Analysis Program) ve EMS 1.3 (Efficiency Measurement System) olmak üzere iki paket program kullanılmıştır.

\section{BULGULAR}

VZA'da kullanılan girdi değişkenlerin her birinin bir çıktı değişkeni, aynı şekilde çıktı değişkenlerinin her birinin de bir girdi değişkeniyle ilişkili olması gerekir (Reynolds ve Thompson 2007). Tek Örneklem Kolmogorov-Smirnov Test sonuçlarına göre yüzde 5 anlamlılık düzeyinde malzeme maliyeti ve düzeltilmiş brüt kâr verileri normal dağılıma uymamaktadır $(\mathrm{p}<, 05)$. Bu nedenle VZA kullanılacak uygun girdi ve çıktı değişkenlerinin belirlenmesi için Spearman Korelâsyon analizi yapılmış ve Tablo 2'de yer alan sonuçlar elde edilmiştir. Tabloda görüldügü gibi ilgili değişkenlerden zorluk değişkeni hariç diğer tüm değişkenler arasında istatistiksel olarak anlamlı bir ilişki tespit edilmiştir. Diğer taraftan alanyazınında nispeten az kullanılmış olan gelir değişkeni ile diğer olası değişkenler (klasik brüt kâr ve düzeltilmiş brüt kâr) arasında çok yüksek düzeyde $(0,938$ ve üzerinde) bir ilişki oraya çıkmıştır. Bu nedenle gelir değişkeni analizden çıkartılmıştır. Böylece VZA'da nihai girdi değişkenleri olarak fiyat, düzeltilmiş maliyet ve faaliyet süresi; çıktı değişkenleri olarak ise satış hacmi, düzeltilmiş brüt kar ve tabak tüketim miktarı verileri kullanılmıştır.

Belirlenen girdi ve çıktı değişkenleri ile yapılan girdi odaklı BCC-VZA sonuçları Tablo 3'te gösterilmektedir. VZA sonuçları temel olarak etkin ve etkin olmayan şeklinde iki tür veri vermektedir. Eğer KB etkinlik değeri 1 ise etkin yani istenen, 1'den küçük ise etkin değil yani geliştirilmesi gereken olarak nitelendirilmektedir. Tablo 3'te görüldüğü üzere menü kalemlerinin 16's1 etkin, $14^{\prime}$ ü ise etkin değildir. Tek başına bu sonuca göre restoran menüsünün yarısından fazlasının (yüzde 53,33) performans bakımından iyi olduğu düşünülebilir. Ancak yiyecek grupları bazında bakıldığında en etkin menü kalemleri arasında 
Tablo 2. Girdi ve Çıktı Değişkenleri Spearman Korelâsyon Analizi Sonuçları (n:30)

\begin{tabular}{|c|c|c|c|c|c|c|c|c|c|c|}
\hline Değişkenler & 1 & 2 & 3 & 4 & 5 & 6 & 7 & 8 & 9 & 10 \\
\hline 1. Fiyat & 1,000 & & & & & & & & & \\
\hline 2. Malzeme Maliyeti &, $864 * *$ & 1,000 & & & & & & & & \\
\hline 3. Düzeltilmiş Maliyet & ,918** &, $951 * *$ & 1,000 & & & & & & & \\
\hline 4. Zorluk & 115 & ,058 & 155 & 1,000 & & & & & & \\
\hline 5. Faaliyet Süresi &, $738 * *$ &, $603 * *$ &, $782 * *$ & ,400* & 1,000 & & & & & \\
\hline 6. Satış hacmi (Popülarite) &, $566^{* *}$ &, $568 * *$ &, $567^{* *}$ & ,070 & ,449* & 1,000 & & & & \\
\hline 7. Brüt Kâr &, $857^{* *}$ &, $712^{* *}$ &, $777^{* *}$ & ,096 &, $705^{* *}$ &, $856 * *$ & 1,000 & & & \\
\hline 8. Düzeltilmiş Brüt Kâr &, $851^{* *}$ &, $664^{* *}$ &, $709 * *$ &,- 010 &, $595^{* *}$ &, $790 * *$ &, $964 * *$ & 1,000 & & \\
\hline 9. Toplam Gelir &, $886 * *$ &, $818 * *$ &, $855 * *$ & ,086 &, $695 * *$ &, $862^{* *}$ &, $977^{* *}$ &, $938^{* *}$ & 1,000 & \\
\hline 10. Yiyecek Tüketimi &, $435^{*}$ &, $438^{*}$ &, $446^{*}$ & ,134 &, $408^{*}$ & ,204 & ,330 & ,300 & ,353 & 1,000 \\
\hline
\end{tabular}

ana yemek grubunun hâkimiyetinin bulunmad1ğ1 görülmektedir. Bu grupta yer alan yiyeceklerde etkinlik oranı yaklaşık yüzde 20 (2/10) ile en düşük seviyededir. Bu sonuç işletme açısından oldukça olumsuz bir durumdur. Çünkü ana yiyecek grubunda yer alan yiyecekler, bir restoran faaliyetinin en temel unsurlarından biri olarak kabul edilmektedir (Kivela 2003). Dolayısıyla ilgili işletmede menü etkinliğinin kapsamlı olarak geliştirilmesi için öncelikle ana yemek grubunda yer alan yemekler üzerinde odaklanılması gerekmektedir. Tatlı grubunda yer alan yiyecekler ise ana yemek grubunda yer alan yiyeceklerden çok daha farklı bir performans ortaya koymuştur. Analiz sonuçlarına göre $\mathrm{C} 1$ tatlı kalemi haricinde tüm tatlılar (sekiz menü kalemi) etkin olarak belirlenmiş̧ir. Başlangıç grubunda yer alan yiyeceklerde ise etkinlik oranı yaklaşık yüzde 55 (6/11) düzeyindedir.

VZA etkin olan menü kalemleri dâhil tüm yiyeceklerin etkinlik bakımından sıralanması için EMS programında ayrıca "süper etkinlik" yapılmış ve elde edilen sonuçlar aynı tabloda gösterilmiştir. Tabloya bakıldığında etkinlik bakımından en yüksek üç menü kalemi sırasıyla B3, C9 ve A4 olmuştur. Buna karşın etkinlik değeri en düşük olan menü kalemleri ise B7, B6 ve A3 olarak belirlenmiştir. Etkin olan ve olmayan menü kalemleri sayısının bir birine yakın olması, en etkin menü kalemleri içinde her bir yiyecek grubunda yer alan yiyecekler olması ilgili menü kalemlerinin kendi içinde rekabetçi bir yapıya sahip olduğunu göstermektedir.

VZA-MA sonuçlarının diğer menü analiz sonuçlarına göre en belirgin avantajlarından biri, etkin olmayan menü kalemlerinin etkin olabilmesi için sayısal hedefler ortaya koyabilmesidir. Örneğin, Tablo 3'te görüldüğü üzere etkin olmayan A2 menü kaleminin fiyatının 15,34 TL, düzeltilmiş maliyet tutarının 7,47 TL ve toplam faaliyet süresinin 16,8 dakika olması 16,8 dakika olması durumunda, mevcut çıktı değerleriyle etkin olabilecektir. Bunun anlamı 19 TL olan fiyatın, 9, 26 TL olan geliştirilmiş maliyet tutarının ve 21 dakika olan faaliyet süresinin yaklaşık olarak yaklaşık olarak yüzde 19-20 düzeylerinde azaltılmasıdır. Diğer etkin olmayan menü kalemleri için belirlenen girdi hedefleri de aynı şekilde ilgili tabloda gösterilmektedir.

\section{SONUÇ VE ÖNERILER}

Finansal ve finansal olmayan verilerle yapılan menü analizi sonunda üç grup ve toplam 30 menü kaleminden oluşan akşam yemeği menüsünün yarısından fazlasının (yüzde 53) etkin olduğu sonucuna varılmıştır. Yazında özellikle son on yıl içinde yapılmış benzer çalışmalarda menü etkinlik oranı yaklaşık yüzde 35-38 arasında ortaya 
Vedat Yiğitoğlu - G. Nilüfer Tetik

Tablo 3. VZA ile Yapılan Menü Analizinin Genel Sonuçları

\begin{tabular}{|c|c|c|c|c|c|c|c|}
\hline$K B$ & $\begin{array}{c}\text { Etkinlik } \\
\text { Skoru (*) }\end{array}$ & $\begin{array}{c}\text { Referans } \\
\text { Sayısı }\end{array}$ & $\begin{array}{c}\text { Hedef } \\
\text { Fiyat (TL) }\end{array}$ & $\begin{array}{c}\text { Hedef } \\
\text { Maliyet (TL) }\end{array}$ & $\begin{array}{c}\text { Hedef } \\
\text { Faaliyet } \\
\text { Süresi (dk) }\end{array}$ & $\begin{array}{c}\text { Süper } \\
\text { Etkinlik Skoru }\end{array}$ & $\begin{array}{l}\text { Etkinlik } \\
\text { Sırası }\end{array}$ \\
\hline A1 & 1,00 & 3 & 27,00 & 18,24 & 20,00 & 1,18 & 4 \\
\hline A2 & 0,81 & 0 & 15,34 & 7,47 & 16,81 & 0,81 & 20 \\
\hline A3 & 0,65 & 0 & 19,34 & 9,91 & 15,49 & 0,65 & 28 \\
\hline A4 & 1,00 & 7 & 17,00 & 5,30 & 15,00 & 1,31 & 3 \\
\hline A5 & 1,00 & 0 & 22,00 & 11,68 & 24,00 & 1,01 & 11 \\
\hline A6 & 0,94 & 0 & 19,70 & 9,68 & 20,64 & 0,94 & 19 \\
\hline A7 & 1,00 & 1 & 25,00 & 10,43 & 17,00 & 1,03 & 10 \\
\hline A8 & 0,69 & 0 & 16,60 & 6,74 & 15,90 & 0,69 & 25 \\
\hline A9 & 0,79 & 0 & 17,38 & 8,42 & 17,38 & 0,79 & 21 \\
\hline A10 & 1,00 & 0 & 19,00 & 8,59 & 21,00 & 1,03 & 9 \\
\hline A11 & 1,00 & 5 & 25,00 & 14,12 & 14,00 & 1,12 & 6 \\
\hline B1 & 0,74 & 0 & 24,44 & 11,64 & 22,79 & 0,74 & 23 \\
\hline B2 & 0,65 & 0 & 18,79 & 9,00 & 19,54 & 0,65 & 27 \\
\hline B3 & 1,00 & 14 & 43,00 & 19,58 & 35,00 & big ** & 1 \\
\hline B4 & 0,75 & 0 & 32,80 & 14,27 & 28,00 & 0,75 & 22 \\
\hline B5 & 0,67 & 0 & 28,61 & 13,55 & 24,84 & 0,67 & 26 \\
\hline B6 & 0,45 & 0 & 15,60 & 7,61 & 17,50 & 0,45 & 29 \\
\hline B7 & 0,43 & 0 & 17,23 & 9,48 & 17,29 & 0,43 & 30 \\
\hline B8 & 0,97 & 0 & 30,42 & 14,95 & 26,11 & 0,97 & 18 \\
\hline B9 & 1,00 & 1 & 37,00 & 12,08 & 30,00 & 1,10 & 7 \\
\hline B10 & 0,71 & 0 & 20,17 & 7,74 & 17,76 & 0,71 & 24 \\
\hline $\mathrm{C} 1$ & 0,99 & 0 & 17,04 & 8,14 & 17,88 & 0,99 & 17 \\
\hline $\mathrm{C} 2$ & 1,00 & 0 & 14,00 & 7,21 & 17,13 & 1,00 & 16 \\
\hline $\mathrm{C3}$ & 1,00 & 0 & 14,00 & 6,98 & 16,27 & 1,00 & 15 \\
\hline C4 & 1,00 & 2 & 14,00 & 9,79 & 24,00 & 1,09 & 8 \\
\hline $\mathrm{C5}$ & 1,00 & 0 & 14,00 & 6,87 & 16,63 & 1,00 & 14 \\
\hline C6 & 1,00 & 0 & 14,00 & 7,00 & 16,19 & 1,00 & 13 \\
\hline C7 & 1,00 & 0 & 14,00 & 6,80 & 16,83 & 1,00 & 12 \\
\hline C8 & 1,00 & 11 & 14,00 & 6,75 & 17,00 & 1,15 & 5 \\
\hline $\mathrm{C9}$ & 1,00 & 19 & 14,00 & 7,06 & 16,00 & big** & 2 \\
\hline
\end{tabular}

*Etkinlik skor değeri 1 olan KB'ler (menü kalemleri) etkin, 1'in altında olanlar ise etkin değildir.

** Süper etkinlik değeri big olan KB'ler, girdileri rastlantısal olarak geniş miktarlarda arttırıldığında dahi etkin kalmaktadır.

çıkmıştır (Taylor vd. 2009; Fang vd. 2013; Chou ve Fang 2013). Lüks restoranlarda daha ayricalık11 menüler, genellikle uzman personel tarafından özel, lezzetli ve taze malzemeler kullanılarak ha- zırlanmaktadır (Walker 2011). Bu bağlamda ilgili restoran menü etkinliğinin genel olarak daha yüksek düzeylerde ortaya çıkması beklenen bir durumdur. Ancak elde edilen analiz sonuçları- 
na menü grupları bazında bakıldığında en etkin olanların sırasıyla tatlılar (sekiz yiyecek), başlangıçlar (altı yiyecek) ve ana yemekler (iki yiyecek) olduğu görülmektedir. Ana yemek grubunda etkinlik oranın yüzde 20 gibi en düşük düzeyde gerçekleşmesi işletme açısından olumsuz bir durumdur. Bu nedenle restoran yöneticileri öncelikle ana yemek grubunda yer alan yiyecekler üzerinde odaklanmalıdır. Bu kapsamda başta ana yemekler olmak üzere etkin olmayan her bir menü kalemi için verilen fiyat, maliyet ve faaliyet süresi hedeflerinden en uygun olanı ya da olanları referans alınarak bir takım düzenlemeler yapılmalıdır. Bununla birlikte ilgili menü kalemlerinin geliştirilmesi adına etkin menü kalemlerinin menü kartında yerleri, tabak düzenlemesi ve servis şekilleri gibi özellikleri de dikkate alınabilir.

Yapılan VZA uygulamasında yazından farklı olarak ilk defa malzeme maliyet verileri yerine işçilik ve enerji giderlerinin menü maliyetlerine

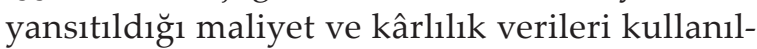
mıştır. Bu sayede elde edilen analiz sonuçlarının kapsam ve güvenirliliği artmıştır (Raab ve Mayer 2007). Diğer taraftan uygulamada tabak tüketimi gibi yeni bir çıktı değişkeninin kullanılmasıyla VZA analiz sürecine, işletme işletme bakış aç1sıyla birlikte konuk bakış açısı da dâhil edilmiştir. Böylece ilgili analiz sonuçları hem kısa hem de uzun vadeli işletme kararlarında kullanılabilir duruma gelmiştir. Çünkü konuk tutum ve davranışları özellikle uzun vadeli işletme başarısının önemli bir göstergesi olarak kabul edilmektedir (Kivela vd. 2003).

Diğer araştırmalarda olduğu gibi bu çalışmada da bir takım sınırlılıklar bulunmaktadır. Araştırmada tek bir restoran örnekleminde durum çalışması yapılmış ve sadece akşam yemeği menüsü dikkate alınmıştır. Bu nedenle elde edilen sonuçların diğer işletmelere genellenmesi mümkün değildir. Bu noktada esas alınması gereken durum, işletme performansı üzerinde etkili olan farklı nitelikte ve farklı nitelikte ve çok sayıda değişkenin menü analiz sürecinde menü analiz sürecinde birlikte kullanılmasıyla daha anlamlı ve güvenilir sonuçların sağlanabilmesidir. Diğer taraftan daha önce ifade edildiği üzere VZA ile el- de edilen elde edilen sonuçlar, analizde kullanılan girdi ve çıktı değişkenlerine dayanmaktadır. Bir işletme için uygun ya da önemli olan bir girdi ya da çıktı unsuru, başka bir işletme için uygun olmayabilir. Bu nedenle farklı yiyecek işletmelerinde, bu işletmelere göre belirlenen farklı değişkenlerle benzer çalışmalar yapılabilir.

\section{KAYNAKÇA}

Atkinson, H. ve Jones, P. (1993). Menu Engineering: Managing the Food Service Micro Marketing Mix, Journal of Restaurant and Foodservice Marketing, 1(1): 37-55.

Baker, M. ve Riley, M. (1994). New Perspectives on Productivity in Hotels: Some Advances and New Directions, International Journal of Hospitality Management, 13(4): 297-311.

Banker, R. D., Charnes, A. ve Cooper, W. W. (1984). Some Models for Estimating Technical and Scale Inefficiencies in Data Envelopment Analysis, Management Science, 30(9): 1078-1092.

Banker, R. D. ve Morey, R. C. (1986). Efficiency Analysis for Exogenously Fixed Inputs and Outputs, Operations Research, 34(4): 513-521.

Bayou, M. E. ve Bennett, L. B. (1992). Profitability Analysis for Table-Service Restaurants, the Cornell Hotel and Restaurant Administration Quarterly, 33(2): 49-55.

Charnes, A., Cooper, W. W. ve Rhodes, E. (1978). Measuring the Efficiency of Decision Making Units, European Journal of Operational Research, 2(6): 429-444.

Chou, S. F. ve Fang, C. Y. (2013). Exploring Surplus-Based Menu Analysis in Chinese-Style Fast Food Restaurants, International Journal of Hospitality Management, 33(1): 263-272.

Connors, P. L. ve Rozell, S. B. (2004). Using a Visual Plate Waste Study to Monitor Menu Performance, Journal of the American Dietetic Association, 104(1): 94-96.

Emrouznejad, A., Parker, B. R. ve Tavares, G. (2008). Evaluation of Research in Efficiency and Productivity: A Survey and Analysis of the First 30 Years of Scholarly Literature in DEA, Socio-Economic Planning Sciences, 42(3): 151-157.

Fakih, K., Assaker, G., Assaf, A. G. ve Hallak, R. (2016). Does Restaurant Menu Information Affect Customer Attitudes and Behavioral Intentions? A Cross-Segment Empirical Analysis Using PLS-SEM, International Journal of Hospitality Management, 57: 71-83.

Fang, C. Y. ve Hsu, F. S. (2012). An Efficiency-Based Metafrontier Approach to Menu Analysis, Journal of Hospitality and Tourism Research, 38(2): 199-221.

Fang, C. Y., Peng, P. Y. ve Pan, W. T. (2013). Does Using an À La Carte or Combo Set Menu Affect the Performance of a Teppanyaki-Style Restaurant?, International Journal of Contemporary Hospitality Management, 25(4): 491-509.

Ferreira, M., Liz Martins, M. ve Rocha, A. (2013). Food Waste as an Index of Food Service Quality, British Food Journal, 115(11): 1628-1637. 
Gupta, S., Mclaughlin, E. ve Gomez, M. (2007). Guest Satisfaction and Restaurant Performance, Cornell Hotel and Restaurant Administration Quarterly, 48(3), 284-298.

Haksever, C. ve Render, B. (2013). Service Management: An Integrated Approach to Supply Chain Management and Operations. New Jersey: FT Press.

Hruschka, H. (1986). Ansätze Der Effizienzmessung von Betrieben, Journal für Betriebswirtschaft, 36(2): 76-85.

Kasavana, M. L. ve Smith D. J. (1982). Menu Engineering. Lansing. MI: Hospitality Publications Inc.

Kivela, J. (2003). Results of a Qualitative Approach to Menu Planning Using Control and Experimental Groups, Journal of Foodservice Business Research, 6(4): 43-65.

Kotschevar, L. H. ve Withrow, D. (2008). Study Guide to Accompany Management by Menu. New Jersey: John Wiley and Sons.

LeBruto, S., Ashley, R. ve Quain, W. (1995). Menu Engineering: A Model Including Labor, Hospitality Review, 13(1): 41-50.

Liu, J. S., Lu, L. Y., Lu, W. M. ve Lin, B. J. (2013). Data Envelopment Analysis 1978-2010: A Citation-Based Literature Survey, Omega, 41(1): 3-15.

Massow, M. ve Mcadams, B. (2015). Table Scraps: An Evaluation of Plate Waste in Restaurants, Journal of Foodservice Business Research, 18(5): 437-453.

Miller, J. E. (1980). Menu Pricing and Strategy. Boston: CBI Publishing.

Morey, R. C. ve Dittman, D. A. (1995). Evalatn A Hotel GM's Performance: A Case Study in Benchmarking, Cornell Hotel and Restaurant Administration Quarterly, 36(5): 3035.

Ninemeier, J. D. (2010). Management of Food and Beverage Operations. Michigan: The Educational Institute of American Hotel and Motel Association.

Özdemir, B. (2012). A Review on Menu Performance Investigation and Some Guiding Propositions, Journal of Food Service Business Research, 15(4): 378-397.

Özdemir, B. ve Çalışkan, O. (2014). A Review of Literature on Restaurant Menus: Specifying the Managerial Issues, International Journal of Gastronomy and Food Science, 2(1): 3-13.
Özdemir, B. ve Nebioğlu, O. (2015). Uygulamada Menü Analizi Nasıl Yapılmaktadır? Beş Yıldızlı Otellerin Mutfak Şeflerinin Görüşleri, Anatolia: Turizm Araştırmaları Dergisi, 26(2): 251-263.

Parkan, C. (1996). Measuring the Performance of Hotel Operations, Socio-Economic Planning Sciences, 30(4): 257-292.

Pavesic, D. V. (1983). Cost/Margin Analysis: A Third Approach to Menu Pricing and Design, International Journal of Hospitality Management, 2(3): 127-134.

Peng, P. Y. J., Fang, C. Y. ve Pan, W.T.W. (2011). EfficiencyBased Menu Analysis in the Teppanyaki-Style Restaurant, The 11th Annual Hawaii International Conference on Business, (ss. 3-12). USA: Hawaii.

Raab, C. ve Mayer, K. (2007). Menu Engineering And Activity-Based Costing-Can They Work Together in A Restaurant?, International Journal of Contemporary Hospitality Management, 19(1): 43-52.

Reynolds, D. ve Taylor, J. (2011). Validating a DEA-Based Menu Analysis Model Using Structural Equation Modelin, International Journal of Hospitality Management, 30(3): 584-587.

Reynolds, D. ve Thompson, G. M. (2007). Multiunit Restaurant Productivity Assessment Using Three-Phase Data Envelopment Analysis, International Journal of Hospitality Management, 26(1): 20-32.

Sherwin, A. J., Nowson, C. A., Mcphee, J., Alexander, J. L., Wark, J. D. ve Flicker, L. (1998). Nutrient Intake at Meals in Residential Care Facilities for the Aged: Validated Visual Estimation of Plate Waste, Australian Journal of Nutrition and Dietetics, 55(4): 188-193.

Taylor, J., Reynolds, D. ve Brown, D. M. (2009). Multi-Factor Menu Analysis Using Data Envelopment Analysis, International Journal of Contemporary Hospitality Management, 21(2): 213-225.

Wagner, J. M. ve Shimshak, D. G. (2007). Stepwise Selection of Variables in Data Envelopment Analysis: Procedures and Managerial Perspectives, European Journal of Operational Research, 180(1): 57-67.

Walker, J. R. (2011). Restaurant Concepts, Management, and Operations. New Jersey: Wiley \& Sons.

Wöber, K. W. (2007). Data Envelopment Analysis, Journal of Travel and Tourism Marketing, 21(4): 91-108. 
Ek 1. VZA'da Kullanılması Düşünülen Girdi ve Çıktı Verileri

\begin{tabular}{|c|c|c|c|c|c|c|c|c|c|c|c|c|}
\hline $\begin{array}{l}\text { Yiyecek } \\
\text { Kalemleri }\end{array}$ & $\begin{array}{l}\text { Satıs } \\
\text { Fiyatı } \\
T L(1)\end{array}$ & $\begin{array}{c}\text { Malzeme } \\
\text { Maliyeti } \\
(T L)(2)\end{array}$ & $\begin{array}{c}\text { Düzeltilmiş } \\
\text { Birim Maliyet } \\
\text { (TL) (3) }\end{array}$ & $\begin{array}{c}\text { Faaliyet } \\
\text { Süresi (dk) }\end{array}$ & $\begin{array}{l}\text { Hazırlık } \\
\text { Zorluk } \\
\text { Derecesi }\end{array}$ & $\begin{array}{l}\text { Satıs Hacmi } \\
\text { (Adet) (4) }\end{array}$ & $\begin{array}{c}\text { Birim Katkı } \\
\text { Payı } \\
(1-2)(5)\end{array}$ & $\begin{array}{c}\text { Düzeltilmiş } \\
\text { Birim Katkı } \\
\text { (1-3) (6) }\end{array}$ & $\begin{array}{c}\text { Brüt Kâr } \\
(4 \times 5)\end{array}$ & $\begin{array}{c}\text { Düzeltilmiş } \\
\text { Brüt Kâr (4x6) }\end{array}$ & $\begin{array}{c}\text { Toplam Satış } \\
\text { Geliri (TL) } \\
(1 \times 4)\end{array}$ & $\begin{array}{l}\text { Yiyecek } \\
\text { Tüketim } \\
\text { Miktarı }\end{array}$ \\
\hline A1 & 27 & 13,08 & 18,24 & 20 & 2,00 & 180 & 13,92 & 8,76 & 2505,6 & 1576,80 & 4860 & 5,75 \\
\hline $\mathrm{A} 2$ & 19 & 4,05 & 9,26 & 21 & 3,00 & 94 & 14,95 & 9,74 & 1405,3 & 915,56 & 1786 & 6,86 \\
\hline A3 & 30 & 12,70 & 18,08 & 24 & 2,50 & 75 & 17,30 & 11,92 & 1297,5 & 894,00 & 2250 & 6,70 \\
\hline A4 & 17 & 2,05 & 5,30 & 15 & 2,50 & 70 & 14,95 & 11,70 & 1046,5 & 819,00 & 1190 & 6,25 \\
\hline A5 & 22 & 6,62 & \begin{tabular}{|l|l|}
11,68 \\
\end{tabular} & 24 & 3,50 & 150 & 15,38 & 10,32 & 2307,0 & 1548,00 & 3300 & 6,83 \\
\hline A6 & 21 & 5,12 & 10,55 & 22 & 2,00 & 138 & 15,88 & 10,45 & 2191,4 & 1442,10 & 2898 & 6,60 \\
\hline A7 & 25 & 6,42 & 10,43 & 17 & 2,50 & 110 & 18,58 & 14,57 & 2043,8 & 1602,70 & 2750 & 6,14 \\
\hline A8 & 24 & 4,75 & 10,08 & 23 & 3,50 & 64 & 19,25 & 13,92 & 1232,0 & 890,88 & 1536 & 6,60 \\
\hline A9 & 22 & 6,46 & 11,57 & 22 & 2,50 & 112 & 15,54 & 10,43 & 1740,5 & 1168,16 & 2464 & 6,33 \\
\hline A10 & 19 & 3,54 & 8,59 & 21 & 2,50 & 142 & 15,46 & 10,41 & 2195,3 & 1478,22 & 2698 & 6,00 \\
\hline A11 & 25 & 11,25 & 14,12 & 14 & 1,50 & 82 & 13,75 & 10,88 & 1127,5 & 892,16 & 2050 & 6,50 \\
\hline B1 & 45 & 26,08 & 32,78 & 31 & 4,50 & 164 & 18,92 & 12,22 & 3102,9 & 2004,08 & 7380 & 6,85 \\
\hline B2 & 29 & 6,15 & 14,75 & 36 & 3,50 & 122 & 22,85 & 14,25 & 2787,7 & 1738,50 & 3538 & 6,45 \\
\hline B3 & 43 & 11,68 & 19,58 & 35 & 3,50 & 292 & 31,32 & 23,42 & 9145,4 & 6838,64 & 12556 & 6,62 \\
\hline B4 & 44 & 10,16 & 19,15 & 40 & 4,00 & 178 & 33,84 & 24,85 & 6023,5 & 4423,30 & 7832 & 6,64 \\
\hline B5 & 43 & 12,75 & 21,08 & 37 & 3,50 & 164 & 30,25 & 21,92 & 4961,0 & 3594,88 & 7052 & 6,78 \\
\hline B6 & 35 & 11,05 & 21,35 & 46 & 3,50 & 78 & 23,95 & 13,65 & 1868,1 & 1064,70 & 2730 & 6,44 \\
\hline B7 & 41 & 21,55 & 32,65 & 40 & 4,00 & 114 & 19,45 & 8,35 & 2217,3 & 951,90 & 4674 & 6,76 \\
\hline B8 & 50 & 24,27 & 31,39 & 27 & 4,00 & 205 & 25,73 & 18,61 & 5274,7 & 3815,05 & 10250 & 6,63 \\
\hline B9 & 37 & 5,60 & 12,08 & 30 & 2,50 & 168 & 31,40 & 24,92 & 5275,2 & 4186,56 & 6216 & 6,18 \\
\hline B10 & 32 & 4,38 & 10,90 & 25 & 2,50 & 75 & 27,62 & 21,10 & 2071,5 & 1582,50 & 2400 & 6,43 \\
\hline C1 & 19 & 4,44 & 8,19 & 18 & 2,50 & 116 & 14,56 & 10,81 & 1689,0 & 1253,96 & 2204 & 6,50 \\
\hline C2 & 14 & 2,74 & 7,52 & 19 & 4,50 & 102 & 11,26 & 6,48 & 1148,5 & 660,96 & 1428 & 6,50 \\
\hline C3 & 14 & 4,18 & 9,18 & 20 & 3,00 & 98 & 9,82 & 4,82 & 962,4 & 472,36 & 1372 & 5,80 \\
\hline C4 & 14 & 4,24 & 9,79 & 24 & 3,50 & 113 & 9,76 & 4,21 & 1102,9 & 475,73 & 1582 & 6,33 \\
\hline C5 & 14 & 2,85 & 8,06 & 21 & 3,00 & 38 & 11,15 & 5,94 & 423,7 & 225,72 & 532 & 6,25 \\
\hline C6 & 14 & 3,82 & 7,35 & 17 & 4,50 & 56 & 10,18 & 6,65 & 570,1 & 372,40 & 784 & 6,00 \\
\hline C7 & 14 & 2,35 & 6,86 & 20 & 4,50 & 70 & 11,65 & 7,14 & 815,5 & 499,80 & 980 & 6,00 \\
\hline C8 & 14 & 3,22 & 6,75 & 17 & 3,50 & 114 & 10,78 & 7,25 & 1228,9 & 826,50 & 1596 & 5,80 \\
\hline C9 & 14 & 3,75 & $\begin{array}{ll}7,06 \\
\end{array}$ & 16 & 1,50 & 92 & 10,25 & 6,94 & 943,0 & 638,48 & 1288 & 7,00 \\
\hline
\end{tabular}
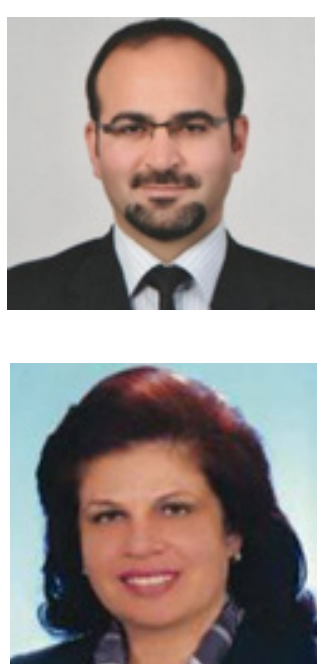

Vedat YiĞiToĞLU

Mersin Üniversitesi Turizm İşletmeciliği ve Otelcilik Yüksekokulu'ndan mezun oldu (1999). Yüksek lisans derecesini Mersin Üniversitesi (2009), doktora derecesini ise Akdeniz Üniversitesi Sosyal Bilimler Enstitüsü Turizm İsletmeciliği ve Otelcilik Ana Bilim Dalı'ndan aldı (2016). Halen Akdeniz Üniversitesi Manavgat Turizm Fakültesi Gastronomi ve Mutfak Sanatları Bölümü’nde doktor öğretim üyesi olarak görev yapmaktadır. Temel çalışma alanları turizm işletmeciliği, performans analizi ve turist davranışıdır.

\section{G. Nilüfer TETiK}

Gazi Üniversitesi Ankara iktisadi ve Ticari ilimler Fakültesi İşletme Fakültesi'nden mezun oldu (1980). Bütünleşik doktora derecesini Gazi Üniversitesi Sosyal Bilimler Enstitüsü Muhasebe Ana Bilim Dalı'ndan aldı (1989). Doçentlik unvanını muhasebe alanından aldı (2003). Profesörlüğe Akdeniz Üniversitesi'nde yükseltildi (2009). Akdeniz Üniversitesi Turizm Fakültesi'nde görev yaptıktan sonra emekli oldu (2019). Temel çalışma alanları genel muhasebe, yönetim muhasebesi ve mali tablolar analizidir. 